\title{
Genetics of Prader-Willi syndrome and Prader-Will-Like syndrome
}

\author{
Chong Kun Cheon, MD, PhD \\ Division of Pediatric Endocrinology \\ and Metabolism, Department of \\ Pediatrics, Pusan National University \\ Children's Hospital, Pusan National \\ University School of Medicine, \\ Yangsan, Korea
}

The Prader-Willi syndrome (PWS) is a human imprinting disorder resulting from genomic alterations that inactivate imprinted, paternally expressed genes in human chromosome region 15q11-q13. This genetic condition appears to be a contiguous gene syndrome caused by the loss of at least 2 of a number of genes expressed exclusively from the paternal allele, including SNRPN, MKRN3, MAGEL2, NDN and several snoRNAs, but it is not yet well known which specific genes in this region are associated with this syndrome. Prader-Will-Like syndrome (PWLS) share features of the PWS phenotype and the gene functions disrupted in PWLS are likely to lie in genetic pathways that are important for the development of PWS phenotype. However, the genetic basis of these rare disorders differs and the absence of a correct diagnosis may worsen the prognosis of these individuals due to the endocrine-metabolic malfunctioning associated with the PWS. Therefore, clinicians face a challenge in determining when to request the specific molecular test used to identify patients with classical PWS because the signs and symptoms of PWS are common to other syndromes such as PWLS. This review aims to provide an overview of current knowledge relating to the genetics of PWS and PWLS, with an emphasis on identification of patients that may benefit from further investigation and genetic screening.

Keywords: Prader-Willi syndrome, Prader-Willi-like syndrome, Imprinting disorder, Genetic screening

\section{Introduction}

Prader-Willi syndrome (PWS; OMIM \#176270) is an imprinted neurobehavioral condition affecting many organ systems and occurs due to the absence of expression of a cluster of paternally expressed genes located at $15 q 11-q 13^{1)}$. PWS is characterized by 2 phases in terms of clinical features. In infancy there is a failure to thrive, muscular hypotonia, genital hypoplasia, respiratory problems, and feeding difficulties ${ }^{2)}$. From as early as 2 years of age, an altered phenotype becomes apparent with evidence of mild developmental delay and learning disabilities and the onset of severe overeating behavior resulting from an abnormal satiety response to food intake $e^{3)}$. Other later-phase phenotypic characteristics include growth hormone deficiency, short stature, small hands and feet and significant behavioral problems ${ }^{1,2}$. Recent epidemiological study estimates an incidence of 1 in 25,000 births and a population prevalence of 1 in $50,000^{4)}$. Paternally expressed genes are particularly important in hypothalamic development, as indicated by the hypothalamic accumulation of androgenetic (duplicated paternal genome) cells in chimeric mouse embryos ${ }^{5,6)}$. Paternal $d e$ novo deletions of the $15 \mathrm{q}-\mathrm{q} 13$ region account for about $70 \%$ of PWS. Most of the remaining cases have uniparental maternal disomy (UPD) for chromosome 15. The PWS region includes a few protein-coding genes and multiple paternally expressed noncoding RNAs, several of which were previously suggested to regulate alternative splicing ${ }^{7,8)}$. Several imprinted genes 
or transcripts have been mapped to15q11-q13, most with only paternal expression, including SNURF-SNRPN, several clusters of small nucleolar RNAs (snoRNAs), NDN, MKRN3, NPAP1, and $M A G E L 2^{9)}$. The noncoding RNAs are highly expressed in the brain and function through modification of ribosomal RNAs $^{10)}$. Nevertheless, the functions of the vast majority of genes residing in the PWS region remain to be determined. The syndrome has a clinical overlap with other diseases, which makes it difficult to accurately diagnose. The challenge for clinicians is not only to differentiate more clearly between PWS and the various Prader-Will-Like syndrome (PWLS) on a clinical level but also to provide conclusive genetic explanations for these phenotypes to provide accurate genetic counseling and treatment. The absence of a correct diagnosis may worsen the prognosis of these individuals due to the endocrine-metabolic malfunctioning associated with the PWS. Therefore, an accurate chromosomal investigation is necessary to differentiate classical PWS from the PWLS. This review aims to provide an overview of current knowledge relating to the genetics of PWS and PWLS.

\section{Molecular and genetic basis of PWS}

\section{Structure and genes in the $15 q 11-q 13$ region}

The 15q11.2-q13 region can be roughly divided into 4 distinct regions that are delineated by 3 common deletion breakpoints $^{11)}$, which lie within segmental duplications ${ }^{12)}$ (Fig. 1). First, proximal nonimprinted region between the 2 common proximal breakpoints (BP I and BP II) containing four bi-parentally expressed genes, NIPA1, NIPA2, CYF1P1, and $T U B G C P 5^{13)}$. Second, the PWS domain contains five paternally expressed protein-coding genes (MKRN3, MAGEL2, NDN, snoRNAs, and SNRPN-SNURF, C15orf2) and several antisense transcripts (including the antisense transcript to $U B E 3 A)^{9,14)}$ Third, the Angelman syndrome (AS) domain containing the preferentially maternally expressed genes (MEGs) (ATP10A and $U B E 3)$. Fourth, a distal nonimprinted region containing a cluster of three gamma-aminobutyric acid receptor genes, the gene for oculocutaneous albinism type 2 (OCA2), HERC2, and the common distal breakpoint (BP III).

The genomic and epigenetic changes causing PWS all lead to a loss of expression of the normally paternally expressed genes on chromosome 15q11.2-q13 ${ }^{15}$. Absence of the paternally inherited copy of these genes, or failure to express them, causes total absence of expression for those genes in the affected individual because the maternal contribution for these genes has been programmed by epigenetic factors to be silenced ${ }^{16)}$. The $15 \mathrm{q} 11.2-\mathrm{q} 13$ region is highly vulnerable to structural rearrangements, such as deletions, duplications, supernumerary marker chromosomes, and translocations due to presence of low-copy repeats (LCRs) in the region ${ }^{17,18)}$. The exact function of each of the genes in determining the PWS phenotype remains to be elucidated, although possible insight has been gained by work with mouse models by multiple investigators ${ }^{15)}$.

\section{Allelic variants related to PWS}

PWS is a contiguous gene disorder, as studies thus far indicate that the complete phenotype is due to the loss of expression of several genes ${ }^{15)}$. The search for candidate genes contributing to specific phenotypic components of PWS has been extensively performed.

\section{1) SNURF-SNRPN gene}

Central to the PWS region is the SNURF-SNRPN gene which is an extremely complex gene locus that spans, $465 \mathrm{~kb}$, with 148 possible exons that undergo alternative splicing ${ }^{4,19)}$. It is a bicistronic gene encoding two different proteins ${ }^{15}$. Exons $4-10$ were described first and encode the protein $S m N$, which is a spliceosomal protein involved in mRNA splicing ${ }^{20)}$. SNURF is encoded by exons $1-3$, which produces a polypeptide of

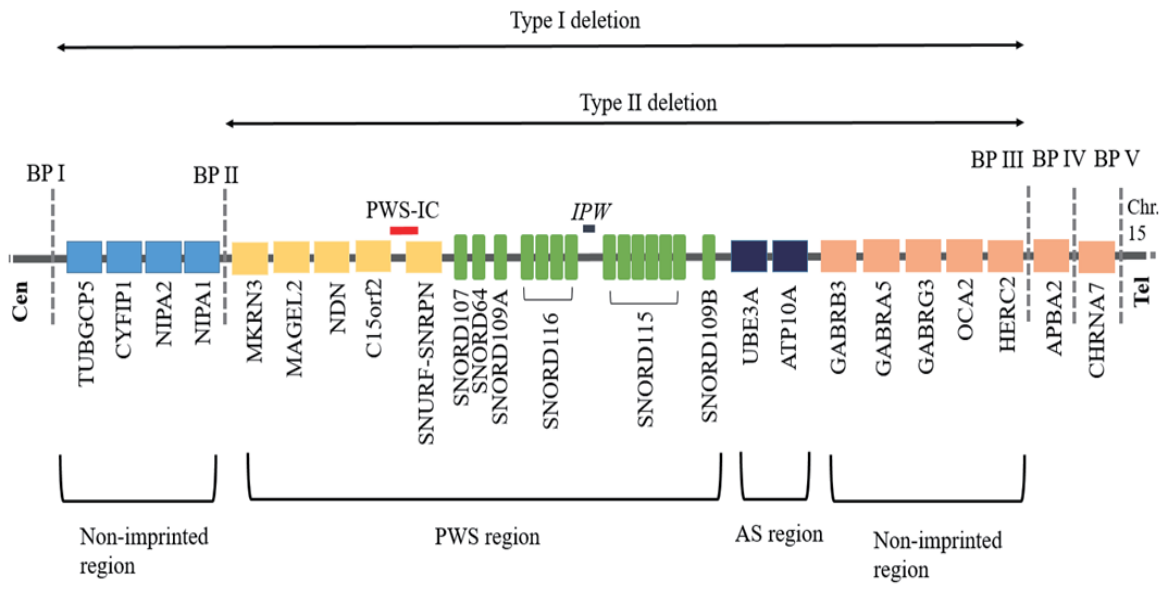

Fig. 1. Ideogram of chromosome 15q11-q13 showing genes located in the typical deletion region of Prader-Willi syndrome. BP, breakpoint; PWS-IC, Prader-Willi syndrome-imprinting center; AS, Angelman syndrome. 
unknown function ${ }^{21)}$. At the 5 end of the SNURF-SNRPN gene is a CpG island encompassing the promoter, exon 1, and intron $1^{15)}$. Imprinting occurs partly through parent-of-origin allelespecific methylation of $\mathrm{CpG}$ residues, which is established either during or after gametogenesis and maintained throughout embryogenesis ${ }^{22}$. This is a differentially methylated region, which is unmethylated on the paternally inherited expressed allele and methylated on the maternally inherited repressed allele $^{20)}$. The SNRPN minimal promotor region includes 71 bp of upstream sequence and the first 51 bp of SNURFSNRPN exon $1^{23,24)}$ and the integrity of the SNRPN minimal promoter region/exon 1 region appears to be essential part of the imprinting center (IC) in the PWS chromosomal region in both mice and humans, and upstream sequences are critical for the correct function of either mechanism ${ }^{25,26)}$. The SNURFSNRPN gene also serves as the host for the six snoRNA genes which are regulated by the expression of SNURF-SNRPN and do not encode proteins ${ }^{19,27,28)}$. Changes in the noncoding regions can cause genetic disease by altering gene expression. Wu et al. ${ }^{29)}$ showed that mutations upstream of SNRPN/exon1 caused lack of methylation in the maternal SNRPN promoter and activation of MEGs including a rescue from the lethality and growth retardation normally shown by the PWS mouse. Maina et al. ${ }^{23)}$ suggested that changes in the maternal SNRPN minimal promotor region may ameliorate some of the more severe symptoms of the disease shown by 9 PWS patients with atypical genetics.

\section{2) SnoRNA genes}

The snoRNA genes located in the large SNURF-SNRPN transcripts present not only in single copy (SNORD64, SNORD107, SNORD108, SNORD109A, and SNORD109B) and but also in the two snoRNA gene clusters (SNORD115 and SNORD116), ${ }^{9,15)}$. It is thought that the snoRNAs may target cellular mRNAs for methylation or alternative splicing because the snoRNAs in the PWS region lack the usual rRNA complementarity and that each snoRNA gene might have multiple targets ${ }^{19,27}$. The snoRNA gene may be responsible for at least several features of PWS on the basis of 6 patients with balanced translocations affecting the SNURF-SNRPN locus, who were described to have typical PWS or a PWLS phenotype ${ }^{30-32)}$. A "key" region to explain much of the PWS phenotype has been narrowed to the SNORD116 snoRNA gene cluster $^{33)}$. Mice lacking the SNORD116 orthologue display a partial PWS phenotype ${ }^{34}$. The SNORD116 has been shown to be highly conserved in rodents, and Gallagher et al. ${ }^{28)}$ showed that a $121-\mathrm{kb}$ region thought to be critical in PWS contained both SNORD116 and SNORD109, suggesting that these genes may play a major role in the PWS phenotype. Up to date, most reported clinical cases of limited deletion of the SNORD116 cluster associated with PWS have also involved adjacent genes: SNURF-SNRPN or SNORD115 ${ }^{34,35)}$. But, a crucial role for the SNORD115 locus was eliminated by an AS family with a familial microdeletion that included the entire SNORD115 gene cluster and the $U B E 3 A$ locus $^{36)}$. There have been three separate reports of three different individuals with overlapping microdeletions
(175-236 kb) that all encompass the SNORD116 gene cluster $^{34,35)}$. All three have multiple clinical features typical of PWS including neonatal hypotonia, infantile feeding problems, rapid weight gain by 2 years of age, hyperphagia, hypogonadism, developmental delay/intellectual disability, and speech and behavioral problems ${ }^{15}$. However, these three individuals also have features not typical of classical PWS, including tall stature, macrocephaly, lack of a "PWS facial gestalt," and atypical hand features of PWS. More recently, Bieth et al. ${ }^{37)}$ reported the first case of a patient with the highly typical features of PWS who presented a restricted deletion of the SNORD116 region which did not affect the expression of SNURF-SNRPN and did not delete any portion of the SNORD115 locus. This finding in a human case might suggest that a lack of the paternal SNORD116 gene cluster has a determinant role in the pathogenesis of PWS.

\section{3) MAGEL2 gene}

The MAGEL2 is located adjacent to NDN in the human and mouse, with highest expression in mouse at late developmental stages and in the hypothalamus and other brain regions and considered to be a candidate gene for the eating disorder of $\mathrm{PWS}^{38-40)}$. Wevrick et al. ${ }^{41-43)}$ have reported that Magel2-null mice have selected biological findings similar to PWS in humans, including neonatal growth retardation, excessive weight gain after weaning, impaired hypothalamic regulation and reduced fertility. Recently, Schaaf et al. ${ }^{14)}$ reported 2 patients with point mutations in the imprinted MAGEL2 gene in the 15q11-q13 domain causing classic PWS, suggesting that that MAGEL2 loss of function can contribute to several aspects of the PWS phenotype.

\section{4) NDN gene}

Among the imprinted candidate genes for PWS, the gene NDN encoding the MAGE family NECDIN protein proposed to act as a neuronal growth suppressor and antiapoptotic protein in postmitotic ${ }^{44)}$. A mouse $N d n$ knockout model has been reported with similar defects to individuals with PWS ${ }^{45)}$ and mouse Ndn mRNA is expressed predominantly in a subset of postmitotic neurons, with highest levels in the hypothalamus and several other brain regions at late embryonic and early postnatal stages, as well as other tissues ${ }^{46)}$.

\section{5) $M K R N 3$ gene}

The MKRN3 encodes the makorin ring finger protein 3 and the MKRN3 differential allele expression occurs through silencing of the MKRN3 maternal allele, which is associated with 5 CpG island methylation ${ }^{47}$. The functional and physiological relevance of MKRN3 is not well known and despite its location in the PWS critical region, its role in this syndrome is also unclear. Recently, it was investigated if central precocious puberty (CPP) could arise from loss of MKRN3 expression by the paternal allele due to a de novo deletion, maternal UPD or an imprinting defect, mechanisms recognized in the pathogenesis of the PWS ${ }^{48}$. Particularly, a girl with a paternal deletion in $M K R N 3, M A G E L 2$ and NDN genes, who had few features of 
the PWS, was diagnosed as $\mathrm{CPP}^{49)}$. In addition, few cases with the PWS and CPP have been reported ${ }^{50)}$. Potentially, human genomic sequence and global methylation analyses in PWS patients with CPP could establish epigenetic alterations in the pathogenesis of the disorder.

\section{6) $I P W$}

Many long noncoding RNAs (lncRNAs) interact with chromatin-modifying proteins owing to their secondary structure and can recruit chromatin-modifying complexes to specific genomic regions. IPW located within the critical PWSassociated region on chromosome 15 is one of several lncRNAs associated with an imprinted locus, which is considered to be an RNA transcript only, because it does not encode a protein ${ }^{1)}$. Stelzer et al. ${ }^{51)}$ demonstrate that a paternally expressed lncRNA known as $I P W$ has a role in modulating the expression of MEGs and identified a critical role for IPW in modulating the expression of MEGs in trans, which has important implications for the understanding of imprinted gene networks. Loss of imprinted genes in the PWS locus thus leads to an effect in trans of increased expression of imprinted genes in the DLK1-DIO3 locus on chromosome 14, suggesting that there might be crosstalk between imprinted loci.

7) Nonimprinted genes (NIPA1, NIPA2, CYFIP1, and GCP5)

It is unclear whether the four, nonimprinted genes (NIPA1, NIPA2, CYFIP1, and GCP5) localized to the interval between BP I and BP II, contribute towards the PWS phenotype ${ }^{44)}$.

\section{Molecular classes of PWS}

There are 3 main classes of chromosomal abnormalities that lead to PWS: deletion on 15q11-q13, maternal UPD of chromosome 15, or a defect in the IC on 15q11-q13, although gene mutation $(<0.1 \%)$ and balanced translocation $(0.1 \%)$ can also be found ${ }^{52,53)}$.

1) Microdeletion of the chromosome region $15 q 11-q 13$ deletion

Most patients with PWS result from an interstitial microdeletion of the paternally inherited $15 q 11.2-q 13$ region. Deletions occur in about $65 \%-75 \%$ of the patients with PWS and AS. Deletions in PWS and AS are subdivided into 2 main subgroups (types I and II) and the BPs are flanked by LCRs in the $3 \mathrm{BPs}^{12)}$. Two common classes of deletions of the PWS/AS critical region have been described; type I (40\%), approximately $6 \mathrm{Mb}$ in size between BP I and BP III and type II (60\%), spanning $5.3 \mathrm{Mb}$ between BP II and BP III ${ }^{54)}$. Individuals with deletion of type I show a more severe phenotype than type II $^{11,12,55)}$. Both types I and II deletions are almost always de novo events ${ }^{56)}$. These recurrent common interstitial deletions measure approximately $5-6 \mathrm{Mb}$ in size and are due to the presence of multiple copies of tandemly repeated sequences at the common breakpoints (BP I, BP II, and BP III) flanking the deleted region ${ }^{15)}$. These LCRs sequences stretch for approximately 250-400 kb and can cause nonhomologous pairing and aberrant recombination of the $15 \mathrm{q} 11.2-\mathrm{q} 13$ region during meiosis, leading to deletions, duplications, triplications, and inverted dup $(15)^{57)}$. In addition, approximately $8 \%$ of those with a deletion have a unique or atypical sized deletion (i.e., not type I or II) from a variety of etiologies, including an unbalanced translocation ${ }^{56)}$. A deletion that is smaller or larger than typically seen in PWS may affect the phenotype rare and have been important for the delineation of genotype-phenotype correlation ${ }^{9}$.

\section{2) Uniparental disomy of chromosome 15}

Maternal UPD 15 is the situation in which there are 2 chromosomes 15 from the mother and none from the father ${ }^{58)}$. This accounts for approximately $20 \%-30 \%$ of individuals with PWS. Maternal UPD has been shown to be associated with advanced maternal age ${ }^{59,60)}$. Trisomy associated with Robertsonian translocations may resolve to disomy through loss of a chromosome and would result in UPD in 50\% of cases $^{15)}$. UPD can be associated with small supernumerary chromosome 15 markers, and both maternal and paternal UPD 15 have been identified from this situation, although maternal is more common ${ }^{61)}$. The parental origin of these small markers is frequently unknown due to the small size and lack of unique genetic material. It has been estimated that approximately $5 \%$ of small supernumerary markers are associated with $\mathrm{UPD}^{62}$.

\section{3) Imprinting defect}

This molecular class affects the imprinting process on the paternally inherited chromosome 15 and accounts for approximately $1 \%-3 \%$ of individuals with $\mathrm{PWS}^{15)}$. Most IDs result from epigenetic causes (epimutations) and demonstrate a maternal-only DNA methylation pattern despite the presence of both parental alleles (i.e., biparental inheritance) ${ }^{15)}$. DNA sequence changes are not found in these epimutations, and they are thought to be random errors in the imprinting process or in early embryogenesis in the rare cases of somatic mosaicism ${ }^{16)}$. However, approximately $15 \%$ of individuals with an ID are found to have a very small deletion $(7.5$ to $>100 \mathrm{~kb})$ in the PWS IC region located at the $5^{\prime}$ end of the $S N R P N$ gene and promoter (i.e., IC deletion $)^{63)}$. Of these, about half have been inherited from an unaffected father with the IC deletion on his maternally inherited chromosome $15^{15)}$. The other half are de novo IC deletions on the paternally inherited 15 that occur during spermatogenesis in the father or after fertilization ${ }^{59,64)}$.

\section{Genotype-phenotype correlations}

There are no features known to occur exclusively in individuals with one of the genetic classes ${ }^{15}$. However, there are some statistical differences in the frequency or severity of some features between the 2 largest classes (deletion $15 \mathrm{q} 11.2-\mathrm{q} 13$ and UPD $)^{15)}$. Postterm delivery is more common with $\mathrm{UPD}^{65)}$. Individuals with UPD are less likely to have the typical characteristic facial appearance ${ }^{59,60)}$, or skill with jigsaw 
puzzles ${ }^{66)}$. Patients with deletions have a higher frequency of hypopigmentation of skin, hair and eyes due to loss of expression of the nonimprinted $P$ gene that is involved in oculocutaneous albinism $^{59,60)}$. In most studies, those with UPD have a little higher verbal IQ and milder behavior problems $^{67)}$. Interestingly, psychosis and autism spectrum disorders (ASD) are almost shown to PWS adults with UPD rather than deletions ${ }^{68)}$. Recent studies suggest that as many as $62 \%$ of those with UPD develop atypical psychosis compared with $16 \%$ of those with a deletion ${ }^{69}$. PWS subjects with IC mutations appear to have a classical PWS phenotype and might have a similar increased predisposition to psychosis as $\mathrm{UPD}^{70)}$. Torrado et al. ${ }^{71)}$ reported that patients with a deletion type had a higher frequency of need for special feeding techniques, sleep disturbance, hypopigmentation, and speech articulation defects. Several studies have investigated phenotypic characteristics between PWS individuals with type I versus type II deletions, but there has been a lack of consensus among the different studies. For example, Butler et al. ${ }^{72)}$ reported 12 patients with type I deletion showed worse adaptive behavior, more severe compulsive behavior and more impairments in reading, math skills and visual perception than 14 patients with type II deletion. On the other hands, Milner et al. ${ }^{73)}$ did not find any significant phenotypic differences between the 2 main deletion subtypes (type I, $\mathrm{n}=14$; type II, $\mathrm{n}=32$ ). As the genotypephenotype relationships become clearer, it will be clinically important to readily subtype the deletion class ${ }^{56)}$.

\section{Clinical manifestations and molecular genetics of PWLS}

PWLS share features of the PWS phenotype, however the genetic basis of these rare disorders differs. The implication is that the gene functions disrupted in PWLS are likely to lie in genetic pathways that are important for the development of PWS phenotypes. The main clinical manifestations of PWLS were reported including hypotonia, obesity, short extremities, and delayed development ${ }^{74)}$. However, PWLS phenotype is clinically and genetically heterogeneous. Recently, several patients with PWLS (ASD, intellectual disability, and a varying degree of clinical and behavioral features of PWS) were reported in whom four different de novo heterozygous truncating mutations in the MAGEL2 gene were identified which occurred on the paternal allele, suggesting that MAGEL2 is a novel gene causing complex ASD, and MAGEL2 loss of function can contribute to several aspects of the PWS phenotype ${ }^{14)}$. Rocha, et al. ${ }^{52}$ reviewed a total of 117 PWLS patients. Of these patients, 44 had their final genetic diagnosis established. Their most frequent symptoms were obesity (84\%), hyperphagia (72.7\%), mental disability (54.5\%), psychomotor delay (50\%), and hypotonia $(43.18 \%)$. It is important to recognize that signs and symptoms of PWS could also be found in patients who show other types of chromosomal abnormalities. For example, chromosomal abnormaliticoes such as chromosome 14 maternal uniparental disomy ${ }^{75}, 1 \mathrm{p} 36$ monosomy $^{76}$, deletion of $6 \mathrm{q}^{74,77,78)}, 2$ pter deletion ${ }^{79)}, 10 \mathrm{q} 26$ deletion $^{80)}$, paracentric inversion $(\mathrm{X})(\mathrm{q} 26 \mathrm{q} 28)^{81}$, $12 \mathrm{q}$ subtelomere deletions ${ }^{82)}$, Xq27qter disomy, deletion of $3 \mathrm{p} 26.3^{22)}$, fragile $X^{83)}$, fragile $X$ with $47, \mathrm{XYY}^{84)}$, duplication of $\mathrm{X}(\mathrm{q} 21.1-\mathrm{q} 21.31)^{85}$, and a duplication of Xq23-q25 duplication ${ }^{86)}$ could be associated with the PWLS phenotype. Genes that are outside of the PWS region result in PWLS phenotypes, and are thus implicated in important pathways in PWS pathobiology that might require additional research. For example, mutations in SIM1, leptin receptor $(L E P R)$, pro-opiomelanocortin $(P O M C)$, melanocortin 4 receptor $(M C 4 R)$, and more recently, $P O U 3 F 2$ have all been related to severe obesity which suggests a convergence onto the leptin-melanocortin pathway in association with oxytocin ${ }^{87,88)}$. Among them, the SIM1 gene, mapping to the common $6 \mathrm{q} 16.2$ deletion region, has been proposed as a candidate for the obesity observed in all these subjects. The $4.1 \mathrm{Mb}$ critical region for PWS includes SIM1 but also 11 other genes or gene predictions, and the specific role of SIM1 haploinsufficiency in the development of PWS has not definitively been established ${ }^{77)}$. Bonnefond et al. ${ }^{89)}$ sequenced SIM1 gene in 44 children with PWLS features, 198 children with severe early-onset obesity, 568 morbidly obese adults, and 383 controls. They identified 4 rare variants (p.I128T, p.Q152E, p.R581G, and p.T714A) in 4 children with PWLS features (including severe obesity) and 4 other rare variants (p.T46R, p.E62K, p.H323Y, and p.D740H) in 7 morbidly obese adults. Three mutations showed strong loss-of-function effects (p.T46R, p.H323Y, and p.T714A) and were associated with high intra-family risk for obesity, while the variants with mild or no effects on SIMI activity were not associated with obesity within families. It suggested a firm link between SIM1 loss of function and severe obesity associated with, or independent of, PWS-related clinical features ${ }^{53)}$. Al Ageeli et al. ${ }^{90)}$ reported case with SMC15 of paternal origin and PWLS features: motor and intellectual delay, autism, autoaggressivity, attention deficit and excessive eating, obesity, and facial dysmorphism (round face, deep set eyes, narrow palpebral fissures, epicanthus, and upturned nose with broad nasal bridge). A comparative study investigating the prevalence and severity of obsessive-compulsive symptoms (OCS) in PWS and PWLS showed that PWS patients suffered a higher incidence of OCS and more severe symptoms than their PWLS counterparts ${ }^{911}$.

\section{Clinical diagnosis and diagnostic testing}

Even though consensus clinical diagnostic criteria for PWS were established in $1993,17 \%$ of 90 patients with a molecular PWS diagnosis did not fulfill the consensus clinical diagnostic criteria $^{92)}$. Therefore, they suggested new criteria to prompt DNA testing for PWS (cognitive impairment, excessive eating, central obesity, and hypothalamic hypogonadism). DNA methylation analysis is the most efficient way to start the genetic workup if PWS is suspected clinically (Fig. 2). DNA methylation analysis is the only technique that will diagnose PWS in all 3 molecular classes and differentiate PWS from AS in deletion cases, and a methylation analysis consistent with 
PWS is sufficient for clinical diagnosis ${ }^{16,20)}$. The most robust, and now most widely used, assay targets the 5' $\mathrm{CpG}$ island of the SNURF-SNRPN locus, and it will correctly diagnose PWS in more than $99 \%$ of cases ${ }^{20)}$. Although, the methylation analysis is the gold standard technique for detecting PWS, it cannot distinguish the molecular class (i.e., deletion, UPD, or ID). Therefore, cytogenetic analysis should also be performed, not only to look for a 15q11-q13 deletion, but to find other chromosomal abnormalities ${ }^{52}$. For genetic counseling purposes, a chromosomal analysis is also recommended in the proband to discern an interstitial de novo deletion from a balanced or unbalanced chromosomal rearrangement involving the 15q11.2 region. Traditionally, deletions of 15q11.2-q13 have been diagnosed with Fluorescence in situ hybridization (FISH) with the SNRPN probe ${ }^{15}$. With the increasing use of chromosomal microarray (CMA) in clinical genetics, it is possible that arrays may replace FISH analysis for the identification of deletions in PWS and $\mathrm{AS}^{15)}$. CMA will precisely report not only the deletion size, but also additional chromosomal abnormalities elsewhere in the genome, which is anticipated to become increasingly important for genotype-phenotype correlations in the future ${ }^{44)}$. However, CMA will not identify the rare chromosomal rearrangements (translocations and inversions) involving proximal 15 which are detectable by simultaneous karyotype and FISH analysis and are important in recurrence risk determination.

If DNA methylation is positive for PWS (i.e., maternal only imprint), but no deletion is found, the next step is to distinguish between maternal UPD and an ID $^{15)}$. This is accomplished by using DNA polymorphism analysis of chromosome 15 loci on the proband's and parents' DNA, which can diagnose

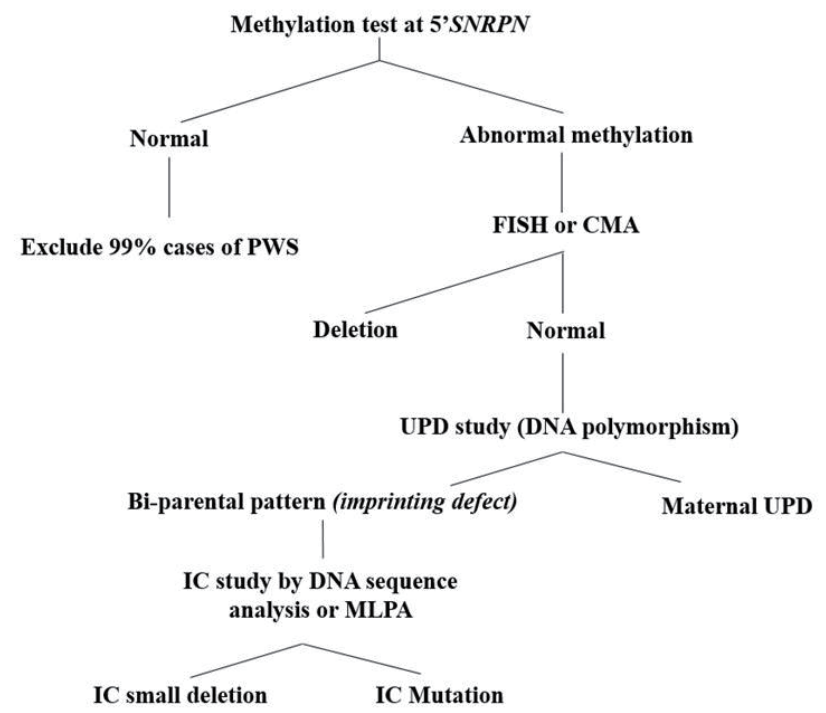

Fig. 2. Diagnostic algorithm in patients suspected of Prader-Willi syndrome (PWS). FISH, fluorescence in situ hybridization; CMA, chromosomal microarray; UPD, uniparental disomy; IC, imprinting center; MLPA, multiplex ligation probe amplification.
UPD in some cases but not all ${ }^{93)}$. If the family polymorphism study reveals that the proband has biparental inheritance of chromosome 15 loci (rather than maternal UPD), then the molecular class is presumed to be an ID $^{15)}$. It is then important to determine whether the ID is due to an epimutation (low recurrence risk) or a small deletion in the $\mathrm{IC}$, as in the later situation the recurrence risk can be as high as 50\% if the father also has an IC deletion ${ }^{15)}$. Approximately $15 \%$ of individuals with PWS due to ID have an IC deletion and approximately 50\% of these are familial mutations ${ }^{78)}$. Testing for IC deletion can be done by sequence analysis at the smallest region of overlap for the PWS IC, which is a region of approximately $4.3 \mathrm{~kb}^{63,78)}$, or by the recently developed methylation-specific multiplex-ligation probe amplification (MS-MLPA) assay. Some laboratories, particularly in Europe, now begin testing for PWS by using the MS-MLPA analysis (rather than single locus DNA methylation analysis at $5^{\prime} S N R P N$ ), with a detection rate of more than $99 \%{ }^{15)}$. Compared to traditional DNA methylation, the advantage of MS-MLPA is that the MS-MLPA will investigate 5 distinct differentially methylated sites rather than just one locus and will give information on dosing in the $15 q 11.2$ region ${ }^{15}$. The latest kit has particularly dense probe coverage for dosing and DNA methylation analysis in the PWS "critical region" between the PWS IC and SNORD $116^{15}$. In addition, the MS-MLPA technique is much more labor/cost-effective than CMA analysis, although CMA provides more precise information regarding the extent of the deletion ${ }^{44)}$. Therefore, MS-MLPA analysis might be considered as the first testing when suspecting AS or PWS as a possible diagnosis, especially since important genotypephenotype correlations will likely be forthcoming ${ }^{44)}$. However, MS-MLPA will also not detect chromosomal rearrangements (inversions and translocations) involving proximal 15, which are detectable by simultaneous karyotype and FISH analysis ${ }^{15)}$.

\section{Genetic counseling}

Understanding the specific genetic etiology in individuals with PWS is vital for the appropriate genetic counseling of affected families ${ }^{15)}$. Estimation of recurrence risk is dependent on the genetic defect causing PWS. Deletion 15q11.2-q13 is sporadic (recurrence risk $<1 \%$ ) except in the rare cases where a chromosomal balanced rearrangement (translocation or inversion) is present in the father ${ }^{94)}$. In these cases, there is a theoretical recurrence risk as high as $25 \%-50 \%$. In addition, a scenario with a risk of $100 \%$ is very unlikely but theoretically possible (i.e., a mother with a 15/15 Robertsonian translocation). Although chromosome rearrangements are the most infrequent genetic cause $(<1 \%)$, it is important to analyze the karyotype of patients suspected of PWS to identify chromosome 15 rearrangements, plus other chromosomal anomalies because the karyotype and FISH analyses carried out in the affected child could give enough information to suspect whether the deletion comes from a chromosome rearrangement ${ }^{95,96)}$. Small supernumerary marker chromosomes have been reported in $\sim 0.3 \%$ of mentally retarded patients ${ }^{97)}$, and in most cases, the 
small supernumerary marker chromosomes could be derived from chromosome 15 , resulting in a UPD ${ }^{61}$. Only in these cases are studies on fathers recommended to offer a thorough genetic counseling ${ }^{98}$. Maternal UPD 15 is typically de novo (recurrence $<1 \%$ ) except if a Robertsonian translocation is present in either parent. If the patient chromosomal analysis is normal, it must be expected that the maternal UPD be sporadic ${ }^{98)}$. Taking together, there are two important considerations. First, the patient chromosomal analysis is also important to identify the presence of small supernumerary marker that could explain some maternal UPD cases. Second, if a Robertsonian translocation is identified in the patient karyotype and suspected as the origin of a maternal UPD, then it is the mother karyotype that must be performed instead of the father one ${ }^{97)}$. Approximately $15 \%$ of those with an imprinting defect have a microdeletion in the IC; this can be familial and has a $50 \%$ recurrence risk when it is ${ }^{977}$. Therefore, fathers of children with an IC deletion should have DNA methylation and dosing analysis (or sequence analysis) to determine whether they carry the IC deletion ${ }^{15}$. However, the greater proportion of those with an imprinting defect have an epigenetic mutation and the recurrence risk is $<1 \%$ for this group $^{98)}$.

\section{Conclusions}

A wide range of genetic conditions are associated with appetite control, body composition, growth, reproduction, learning disability, psychosis and other behavioral problems. As yet, many outstanding questions remains to be answered about these condition although much is being learnt relating to the important contribution of specific genes, and their coded proteins. The genetic complexity of the PWS chromosomal region, with multiple imprinted genes, alternative splice variants, gene duplications and variant copies, and the mechanisms of imprinting itself, are matched by the wide variety of phenotypes that involve multiple organ systems. Updated information regarding the genetics and phenotypic characterization of individuals with PWS and PWLS is important for all physicians and will be helpful in recognizing patients that may benefit from further investigation and genetic screening and anticipating complications associated with this rare obesity-related disorder.

\section{Conflict of interest}

No potential conflict of interest relevant to this article was reported.

\section{References}

1. Murrell A. Cross-talk between imprinted loci in PraderWilli syndrome. Nat Genet 2014;46:528-30.

2. Holm VA, Cassidy SB, Butler MG, Hanchett JM, Greenswag LR, Whitman BY, et al. Prader-Willi syndrome: consensus diagnostic criteria. Pediatrics 1993;91:398-402.
3. Holland AJ, Treasure J, Coskeran P, Dallow J. Characteristics of the eating disorder in Prader-Willi syndrome: implications for treatment. J Intellect Disabil Res 1995;39(Pt 5):373-81.

4. Whittington JE, Holland AJ, Webb T, Butler J, Clarke D, Boer $\mathrm{H}$. Population prevalence and estimated birth incidence and mortality rate for people with Prader-Willi syndrome in one UK Health Region. J Med Genet 2001;38:792-8.

5. Swaab DF. Prader-Willi syndrome and the hypothalamus. Acta Paediatr Suppl 1997;423:50-4.

6. Keverne EB. Genomic imprinting in the brain. Curr Opin Neurobiol 1997;7:463-8.

7. Kishore S, Stamm S. The snoRNA HBII-52 regulates alternative splicing of the serotonin receptor $2 \mathrm{C}$. Science 2006;311:230-2.

8. Yin QF, Yang L, Zhang Y, Xiang JF, Wu YW, Carmichael GG, et al. Long noncoding RNAs with snoRNA ends. Mol Cell 2012;48:219-30.

9. Anderlid BM, Lundin J, Malmgren H, Lehtihet M, Nordgren A. Small mosaic deletion encompassing the snoRNAs and SNURF-SNRPN results in an atypical Prader-Willi syndrome phenotype. Am J Med Genet A 2014;164A:425-31.

10. Cavaillé J, Buiting K, Kiefmann M, Lalande M, Brannan CI, Horsthemke B, et al. Identification of brain-specific and imprinted small nucleolar RNA genes exhibiting an unusual genomic organization. Proc Natl Acad Sci USA 2000;97:14311-6.

11. Christian SL, Robinson WP, Huang B, Mutirangura A, Line MR, Nakao M, et al. Molecular characterization of two proximal deletion breakpoint regions in both PraderWilli and Angelman syndrome patients. Am J Hum Genet 1995;57:40-8.

12. Amos-Landgraf JM, Ji Y, Gottlieb W, Depinet T, Wandstrat AE, Cassidy SB, et al. Chromosome breakage in the PraderWilli and Angelman syndromes involves recombination between large, transcribed repeats at proximal and distal breakpoints. Am J Hum Genet 1999;65:370-86.

13. Chai JH, Locke DP, Greally JM, Knoll JH, Ohta T, Dunai J, et al. Identification of four highly conserved genes between breakpoint hotspots BP1 and BP2 of the Prader-Willi/ Angelman syndromes deletion region that have undergone evolutionary transposition mediated by flanking duplicons. Am J Hum Genet 2003;73:898-925.

14. Schaaf CP, Gonzalez-Garay ML, Xia F, Potocki L, Gripp KW, Zhang B, et al. Truncating mutations of MAGEL2 cause Prader-Willi phenotypes and autism. Nat Genet 2013;45:1405-8.

15. Cassidy SB, Schwartz S, Miller JL, Driscoll DJ. Prader-Willi syndrome. Genet Med 2012;14:10-26.

16. Glenn CC, Driscoll DJ, Yang TP, Nicholls RD. Genomic imprinting: potential function and mechanisms revealed by the Prader-Willi and Angelman syndromes. Mol Hum Reprod 1997;3:321-32.

17. Christian SL, Fantes JA, Mewborn SK, Huang B, Ledbetter DH. Large genomic duplicons map to sites of instability in 
the Prader-Willi/Angelman syndrome chromosome region (15q11-q13). Hum Mol Genet 1999;8:1025-37.

18. Donlon TA, Lalande M, Wyman A, Bruns G, Latt SA. Isolation of molecular probes associated with the chromosome 15 instability in the Prader-Willi syndrome. Proc Natl Acad Sci USA 1986;83:4408-12.

19. Runte M, Hüttenhofer A, Gross S, Kiefmann M, Horsthemke B, Buiting K. The IC-SNURF-SNRPN transcript serves as a host for multiple small nucleolar RNA species and as an antisense RNA for UBE3A. Hum Mol Genet 2001;10:2687-700.

20. Glenn CC, Saitoh S, Jong MT, Filbrandt MM, Surti U, Driscoll DJ, et al. Gene structure, DNA methylation, and imprinted expression of the human SNRPN gene. Am J Hum Genet 1996;58:335-46.

21. Gray TA, Saitoh S, Nicholls RD. An imprinted, mammalian bicistronic transcript encodes two independent proteins. Proc Natl Acad Sci USA 1999;96:5616-21.

22. Geuns E, De Rycke M, Van Steirteghem A, Liebaers I. Methylation imprints of the imprint control region of the SNRPN-gene in human gametes and preimplantation embryos. Hum Mol Genet 2003;12:2873-9.

23. Maina EN, Webb T, Soni S, Whittington J, Boer H, Clarke D, et al. Analysis of candidate imprinted genes in PWS subjects with atypical genetics: a possible inactivating mutation in the SNURF/SNRPN minimal promoter. J Hum Genet 2007;52:297-307.

24. Green Finberg Y, Kantor B, Hershko AY, Razin A. Characterization of the human Snrpn minimal promoter and cis elements within it. Gene 2003;304:201-6.

25. Bielinska B, Blaydes SM, Buiting K, Yang T, KrajewskaWalasek M, Horsthemke B, et al. De novo deletions of SNRPN exon 1 in early human and mouse embryos result in a paternal to maternal imprint switch. Nat Genet 2000;25:74-8.

26. Yang T, Adamson TE, Resnick JL, Leff S, Wevrick R, Francke U, et al. A mouse model for Prader-Willi syndrome imprinting-centre mutations. Nat Genet 1998;19:25-31.

27. de los Santos T, Schweizer J, Rees CA, Francke U. Small evolutionarily conserved RNA, resembling C/D box small nucleolar RNA, is transcribed from PWCR1, a novel imprinted gene in the Prader-Willi deletion region, which Is highly expressed in brain. Am J Hum Genet 2000;67:106782.

28. Gallagher RC, Pils B, Albalwi M, Francke U. Evidence for the role of PWCR1/HBII-85 C/D box small nucleolar RNAs in Prader-Willi syndrome. Am J Hum Genet 2002; 71:669-78

29. Wu MY, Tsai TF, Beaudet AL. Deficiency of Rbbp1/Arid4a and Rbbp1l1/Arid4b alters epigenetic modifications and suppresses an imprinting defect in the PWS/AS domain. Genes Dev 2006;20:2859-70.

30. Wirth J, Back E, Hüttenhofer A, Nothwang HG, Lich C, Gross S, et al. A translocation breakpoint cluster disrupts the newly defined 3' end of the SNURF-SNRPN transcription unit on chromosome 15. Hum Mol Genet 2001;10:201-10.
31. Kuslich CD, Kobori JA, Mohapatra G, Gregorio-King C, Donlon TA. Prader-Willi syndrome is caused by disruption of the SNRPN gene. Am J Hum Genet 1999;64:70-6.

32. Schulze A, Hansen C, Skakkebaek NE, Brøndum-Nielsen $\mathrm{K}$, Ledbeter DH, Tommerup N. Exclusion of SNRPN as a major determinant of Prader-Willi syndrome by a translocation breakpoint. Nat Genet 1996;12:452-4.

33. Buiting K. Prader-Willi syndrome and Angelman syndrome. Am J Med Genet C Semin Med Genet 2010; 154C:365-76.

34. Duker AL, Ballif BC, Bawle EV, Person RE, Mahadevan S, Alliman S, et al. Paternally inherited microdeletion at $15 q 11.2$ confirms a significant role for the SNORD116 C/D box snoRNA cluster in Prader-Willi syndrome. Eur J Hum Genet 2010;18:1196-201.

35. Sahoo T, del Gaudio D, German JR, Shinawi M, Peters SU, Person RE, et al. Prader-Willi phenotype caused by paternal deficiency for the HBII-85 C/D box small nucleolar RNA cluster. Nat Genet 2008;40:719-21.

36. Runte M, Varon R, Horn D, Horsthemke B, Buiting K. Exclusion of the C/D box snoRNA gene cluster HBII-52 from a major role in Prader-Willi syndrome. Hum Genet 2005;116:228-30.

37. Bieth E, Eddiry S, Gaston V, Lorenzini F, Buffet A, Conte Auriol F, et al. Highly restricted deletion of the SNORD116 region is implicated in Prader-Willi Syndrome. Eur J Hum Genet 2015;23:252-5.

38. Lee S, Wevrick R. Identification of novel imprinted transcripts in the Prader-Willi syndrome and Angelman syndrome deletion region: further evidence for regional imprinting control. Am J Hum Genet 2000;66:848-58.

39. Boccaccio I, Glatt-Deeley H, Watrin F, Roëckel N, Lalande M, Muscatelli F. The human MAGEL2 gene and its mouse homologue are paternally expressed and mapped to the Prader-Willi region. Hum Mol Genet 1999;8:2497-505.

40. Lee S, Kozlov S, Hernandez L, Chamberlain SJ, Brannan CI, Stewart CL, et al. Expression and imprinting of MAGEL2 suggest a role in Prader-willi syndrome and the homologous murine imprinting phenotype. Hum Mol Genet 2000;9:1813-9.

41. Tennese AA, Wevrick R. Impaired hypothalamic regulation of endocrine function and delayed counterregulatory response to hypoglycemia in Magel2-null mice. Endocrinology 2011;152:967-78.

42. Mercer RE, Wevrick R. Loss of magel2, a candidate gene for features of Prader-Willi syndrome, impairs reproductive function in mice. PLoS One 2009;4:e4291.

43. Bischof JM, Stewart CL, Wevrick R. Inactivation of the mouse Magel2 gene results in growth abnormalities similar to Prader-Willi syndrome. Hum Mol Genet 2007;16:27139.

44. Pagliardini S, Ren J, Wevrick R, Greer JJ. Developmental abnormalities of neuronal structure and function in prenatal mice lacking the prader-willi syndrome gene necdin. Am J Pathol 2005;167:175-91.

45. Andrieu D, Meziane H, Marly F, Angelats C, Fernandez 
PA, Muscatelli F. Sensory defects in Necdin deficient mice result from a loss of sensory neurons correlated within an increase of developmental programmed cell death. BMC Dev Biol 2006;6:56.

46. Taniguchi N, Taniura H, Niinobe M, Takayama C, Tominaga-Yoshino K, Ogura A, et al. The postmitotic growth suppressor necdin interacts with a calcium-binding protein (NEFA) in neuronal cytoplasm. J Biol Chem 2000;275:31674-81.

47. Hershko A, Razin A, Shemer R. Imprinted methylation and its effect on expression of the mouse Zfp127 gene. Gene 1999;234:323-7.

48. Macedo DB, Abreu AP, Reis AC, Montenegro LR, Dauber A, Beneduzzi D, et al. Central precocious puberty that appears to be sporadic caused by paternally inherited mutations in the imprinted gene makorin ring finger 3. J Clin Endocrinol Metab 2014;99:E1097-103.

49. Kanber D, Giltay J, Wieczorek D, Zogel C, Hochstenbach R, Caliebe A, et al. A paternal deletion of MKRN3, MAGEL2 and NDN does not result in Prader-Willi syndrome. Eur J Hum Genet 2009; 17:582-90.

50. Lee HS, Hwang JS. Central precocious puberty in a girl with Prader-Willi syndrome. J Pediatr Endocrinol Metab 2013;26:1201-4.

51. Stelzer Y, Sagi I, Yanuka O, Eiges R, Benvenisty N. The noncoding RNA IPW regulates the imprinted DLK1-DIO3 locus in an induced pluripotent stem cell model of PraderWilli syndrome. Nat Genet 2014;46:551-7.

52. Rocha CF, Paiva CL. Prader-Willi-like phenotypes: a systematic review of their chromosomal abnormalities. Genet Mol Res 2014;13:2290-8.

53. Nicholls RD, Knepper JL. Genome organization, function, and imprinting in Prader-Willi and Angelman syndromes. Annu Rev Genomics Hum Genet 2001;2:153-75.

54. Butler MG, Fischer W, Kibiryeva N, Bittel DC. Array comparative genomic hybridization $(\mathrm{aCGH})$ analysis in Prader-Willi syndrome. Am J Med Genet A 2008;146A:85460.

55. Roberts SE, Dennis NR, Browne CE, Willatt L, Woods G, Cross I, et al. Characterisation of interstitial duplications and triplications of chromosome 15q11-q13. Hum Genet 2002;110:227-34.

56. Kim SJ, Miller JL, Kuipers PJ, German JR, Beaudet AL, Sahoo T, et al. Unique and atypical deletions in Prader-Willi syndrome reveal distinct phenotypes. Eur J Hum Genet 2012;20:283-90.

57. Robinson WP, Dutly F, Nicholls RD, Bernasconi F, Peñaherrera $\mathrm{M}$, Michaelis $\mathrm{RC}$, et al. The mechanisms involved in formation of deletions and duplications of 15q11-q13. J Med Genet 1998;35:130-6.

58. Yamazawa K, Ogata T, Ferguson-Smith AC. Uniparental disomy and human disease: an overview. Am J Med Genet C Semin Med Genet 2010;154C:329-34.

59. Gillessen-Kaesbach G, Robinson W, Lohmann D, KayaWesterloh S, Passarge E, Horsthemke B. Genotypephenotype correlation in a series of 167 deletion and non- deletion patients with Prader-Willi syndrome. Hum Genet 1995; $96: 638-43$.

60. Cassidy SB, Forsythe M, Heeger S, Nicholls RD, Schork N, Benn P, et al. Comparison of phenotype between patients with Prader-Willi syndrome due to deletion $15 \mathrm{q}$ and uniparental disomy 15. Am J Med Genet 1997;68:433-40.

61. Liehr T, Brude E, Gillessen-Kaesbach G, König R, Mrasek $\mathrm{K}$, von Eggeling F, et al. Prader-Willi syndrome with a karyotype 47,XY,+min(15)(pter->q11.1:) and maternal UPD 15--case report plus review of similar cases. Eur J Med Genet 2005;48:175-81.

62. Kotzot D. Review and meta-analysis of systematic searches for uniparental disomy (UPD) other than UPD 15. Am J Med Genet 2002;111:366-75.

63. Ohta T, Gray TA, Rogan PK, Buiting K, Gabriel JM, Saitoh $\mathrm{S}$, et al. Imprinting-mutation mechanisms in Prader-Willi syndrome. Am J Hum Genet 1999;64:397-413.

64. Buiting K, Gross S, Lich C, Gillessen-Kaesbach G, elMaarri O, Horsthemke B. Epimutations in Prader-Willi and Angelman syndromes: a molecular study of 136 patients with an imprinting defect. Am J Hum Genet 2003;72:571-7.

65. Butler MG, Sturich J, Myers SE, Gold JA, Kimonis V, Driscoll DJ. Is gestation in Prader-Willi syndrome affected by the genetic subtype? J Assist Reprod Genet 2009;26:4616.

66. Dykens EM. Are jigsaw puzzle skills 'spared' in persons with Prader-Willi syndrome? J Child Psychol Psychiatry 2002;43:343-52.

67. Roof E, Stone W, MacLean W, Feurer ID, Thompson T, Butler MG. Intellectual characteristics of Prader-Willi syndrome: comparison of genetic subtypes. J Intellect Disabil Res 2000;44 (Pt 1):25-30.

68. Veltman MW, Thompson RJ, Roberts SE, Thomas NS, Whittington J, Bolton PF. Prader-Willi syndrome: a study comparing deletion and uniparental disomy cases with reference to autism spectrum disorders. Eur Child Adolesc Psychiatry 2004;13:42-50.

69. Soni S, Whittington J, Holland AJ, Webb T, Maina E, Boer $\mathrm{H}$, et al. The course and outcome of psychiatric illness in people with Prader-Willi syndrome: implications for management and treatment. J Intellect Disabil Res 2007:51(Pt 1):32-42.

70. Vogels A, Matthijs G, Legius E, Devriendt K, Fryns JP. Chromosome 15 maternal uniparental disomy and psychosis in Prader-Willi syndrome. J Med Genet 2003;40:72-3.

71. Torrado M, Araoz V, Baialardo E, Abraldes K, Mazza C, Krochik G, et al. Clinical-etiologic correlation in children with Prader-Willi syndrome (PWS): an interdisciplinary study. Am J Med Genet A 2007;143A:460-8.

72. Butler MG, Bittel DC, Kibiryeva N, Talebizadeh Z, Thompson T. Behavioral differences among subjects with Prader-Willi syndrome and type I or type II deletion and maternal disomy. Pediatrics 2004;113(3 Pt 1):565-73.

73. Milner KM, Craig EE, Thompson RJ, Veltman MW, Thomas NS, Roberts S, et al. Prader-Willi syndrome: intellectual 
abilities and behavioural features by genetic subtype. J Child Psychol Psychiatry 2005;46:1089-96.

74. Varela MC, Simões-Sato AY, Kim CA, Bertola DR, De Castro CI, Koiffmann CP. A new case of interstitial 6q16.2 deletion in a patient with Prader-Willi-like phenotype and investigation of SIM1 gene deletion in 87 patients with syndromic obesity. Eur J Med Genet 2006;49:298-305.

75. Hosoki K, Kagami M, Tanaka T, Kubota M, Kurosawa K, Kato M, et al. Maternal uniparental disomy 14 syndrome demonstrates prader-willi syndrome-like phenotype. J Pediatr 2009;155:900-3.e1.

76. Tsuyusaki Y, Yoshihashi H, Furuya N, Adachi M, Osaka H, Yamamoto K, et al. 1p36 deletion syndrome associated with Prader-Willi-like phenotype. Pediatr Int 2010;52:547-50.

77. Bonaglia MC, Ciccone R, Gimelli G, Gimelli S, Marelli S, Verheij J, et al. Detailed phenotype-genotype study in five patients with chromosome $6 q 16$ deletion: narrowing the critical region for Prader-Willi-like phenotype. Eur J Hum Genet 2008;16:1443-9.

78. Izumi K, Housam R, Kapadia C, Stallings VA, Medne L, Shaikh TH, et al. Endocrine phenotype of 6q16.1-q21 deletion involving SIM1 and Prader-Willi syndrome-like features. Am J Med Genet A 2013;161A:3137-43.

79. Doco-Fenzy M, Leroy C, Schneider A, Petit F, Delrue MA Andrieux J, et al. Early-onset obesity and paternal 2pter deletion encompassing the ACP1, TMEM18, and MYT1L genes. Eur J Hum Genet 2014;22:471-9.

80. Lukusa T, Fryns JP. Pure distal monosomy 10q26 in a patient displaying clinical features of Prader-Willi syndrome during infancy and distinct behavioural phenotype in adolescence. Genet Couns 2000;11:119-26.

81. Florez L, Anderson M, Lacassie Y. De novo paracentric inversion $(\mathrm{X})(\mathrm{q} 26 \mathrm{q} 28)$ with features mimicking PraderWilli syndrome. Am J Med Genet A 2003;121A:60-4.

82. Niyazov DM, Nawaz Z, Justice AN, Toriello HV, Martin CL, Adam MP. Genotype/phenotype correlations in two patients with $12 \mathrm{q}$ subtelomere deletions. Am J Med Genet A 2007;143A:2700-5.

83. Nowicki ST, Tassone F, Ono MY, Ferranti J, Croquette MF, Goodlin-Jones B, et al. The Prader-Willi phenotype of fragile X syndrome. J Dev Behav Pediatr 2007;28:133-8.

84. Stalker HJ, Keller KL, Gray BA, Zori RT. Concurrence of fragile X syndrome and 47, XYY in an individual with a Prader-Willi-like phenotype. Am J Med Genet A 2003;116A:176-8.

85. Pramyothin P, Pithukpakorn M, Arakaki RF. A 47, XXY patient and Xq21.31 duplication with features of PraderWilli syndrome: results of array-based comparative genomic hybridization. Endocrine 2010;37:379-82.

86. Monaghan KG, Van Dyke DL, Feldman GL. Prader-Willilike syndrome in a patient with an Xq23q25 duplication.
Am J Med Genet 1998;80:227-31.

87. Heymsfield SB, Avena NM, Baier L, Brantley P, Bray GA, Burnett LC, et al. Hyperphagia: current concepts and future directions proceedings of the 2 nd international conference on hyperphagia. Obesity (Silver Spring) 2014;22 Suppl 1:S1-17.

88. Kasher PR, Schertz KE, Thomas M, Jackson A, Annunziata S, Ballesta-Martinez MJ, et al. Small 6q16.1 Deletions Encompassing POU3F2 Cause Susceptibility to Obesity and Variable Developmental Delay with Intellectual Disability. Am J Hum Genet 2016;98:363-72.

89. Bonnefond A, Raimondo A, Stutzmann F, Ghoussaini M, Ramachandrappa S, Bersten DC, et al. Loss-of-function mutations in SIM1 contribute to obesity and Prader-Willilike features. J Clin Invest 2013;123:3037-41.

90. Al Ageeli E, Drunat S, Delanoë C, Perrin L, Baumann C, Capri Y, et al. Duplication of the 15q11-q13 region: clinical and genetic study of 30 new cases. Eur J Med Genet 2014;57:5-14.

91. State MW, Dykens EM, Rosner B, Martin A, King BH. Obsessive-compulsive symptoms in Prader-Willi and "Prader-Willi-Like" patients. J Am Acad Child Adolesc Psychiatry 1999;38:329-34.

92. Gunay-Aygun M, Schwartz S, Heeger S, O'Riordan MA, Cassidy SB. The changing purpose of Prader-Willi syndrome clinical diagnostic criteria and proposed revised criteria. Pediatrics 2001;108:E92.

93. Shaffer LG, Agan N, Goldberg JD, Ledbetter DH, Longshore JW, Cassidy SB. American College of Medical Genetics statement of diagnostic testing for uniparental disomy. Genet Med 2001;3:206-11.

94. Flori E, Biancalana V, Girard-Lemaire F, Favre R, Flori J, Doray B, et al. Difficulties of genetic counseling and prenatal diagnosis in a consanguineous couple segregating for the same translocation $(14 ; 15)(\mathrm{q} 11 ; \mathrm{q} 13)$ and at risk for Prader-Willi and Angelman syndromes. Eur J Hum Genet 2004;12:181-6.

95. Rego A, Coll MD, Regal M, Guitart M, Escudero T, GarcíaMayor RV. A case with 47,XXY,del(15)(q11;q13) karyotype associated with Prader-Willi phenotype. Horm Res 1997;48:44-6.

96. Verhoeven WM, de Vries BB, Duffels SJ, Egger JI, Noordam C, Tuinier S. Klinefelter's syndrome and PraderWilli syndrome: a rare combination. Psychopathology 2007;40:356-60

97. Camprubí C, Coll MD, Gabau E, Guitart M. Prader-Willi and Angelman syndromes: genetic counseling. Eur J Hum Genet 2010;18:154-5.

98. Cassidy SB, Driscoll DJ. Prader-Willi syndrome. Eur J Hum Genet 2009;17:3-13. 